\title{
Whole body bone mineral accretion in healthy children and adolescents
}

\author{
Christian Mølgaard, Birthe Lykke Thomsen, Kim Fleischer Michaelsen
}

\begin{abstract}
Data on accretion in bone size and bone mineral content (BMC) are needed to evaluate bone mineralisation during childhood. Whole body bone mineral content (BMC) and bone area (BA) were determined by dual energy $x$ ray absorptiometry (Hologic 1000/W) with a one year interval in healthy girls $(n=192)$ and boys $(n=140)$ aged 6-19 years. Annual accretion in BMC $(\triangle \mathrm{BMC}(\mathrm{g} / \mathrm{year}))$ and BA $\left(\Delta \mathrm{BA}\left(\mathrm{cm}^{2} /\right.\right.$ year $\left.)\right)$ according to sex and pubertal stages were calculated. $\triangle \mathrm{BA}$ and $\triangle \mathrm{BMC}$ were highly significantly associated with pubertal stages in girls and boys. Centile curves for $\triangle B A$ and $\triangle B M C$ according to sex and age were constructed using the LMS method. Peak $\triangle B A$ and $\triangle B M C$ values were reached earlier in girls (12.3 and 12.5 years, respectively) than in boys (13.4 and 14.2 years, respectively). The $\triangle \mathrm{BA}$ peak was dissociated in time from the $\triangle B M C$ peak, indicating that increase in bone size occurs before increase in bone mineral content. Assuming that $32.2 \%$ of BMC consist of calcium, the median (90th centile) annual bone calcium accretion in pubertal stage III was $220 \mathrm{mg} /$ day (302) and $317 \mathrm{mg} /$ day (386) for girls and boys, respectively. To obtain an average bone calcium accretion, a high calcium absorption is needed during puberty. This may have implications for dietary calcium requirements at this time. (Arch Dis Child 1999;81:10-15)
\end{abstract}

Keywords: bone growth; bone mineral content; dual energy $x$ ray absorptiometry

Research Department of Human Nutrition and Centre for

Advanced Food Studies, The Royal

Veterinary and

Agricultural

University,

Rolighedsvej 30,

DK-1958

Frederiksberg C,

Denmark

C Mølgaard

K F Michaelsen

Department of

Biostatistics,

University of

Copenhagen,

Blegdamsvej 3 ,

DK-2200 Copenhagen

N, Denmark

B L Thomsen

Correspondence to:

Dr Mølgaard.

Accepted 5 March 1999
Bone growth during childhood and adolescence is of major importance for the size of the peak bone mass. It is generally accepted that those who achieve a higher peak bone mass are less at risk of having an osteoporotic fracture later in life. ${ }^{12}$ Bone calcium accretion has been studied previously by balance studies, ${ }^{34}$ but these only cover short time periods and are difficult in children. Dual energy $x$ ray absorptiometry (DXA) is a non-invasive technique used to measure the amount of hydroxyapatite in bones (bone mineral content; BMC), with high precision and a very low radiation dose. Therefore, repeated DXA scans can be performed in children, making it possible to calculate bone calcium accretion and study the pattern of bone mineralisation during growth.

During puberty there is a considerable increase in bone mass. ${ }^{56}$ Increased bone mass can result either from increase in bone size, bone density, or both. Bone size depends on both bone length and bone width. Recently, Fournier et al have shown an asynchrony between the rates of height gain and gain in regional bone mineral density (lumbar, femoral neck, midfemoral shaft) during puberty, with the former occurring earlier. ${ }^{7}$ The dissociation in time was clearly related to pubertal stage. In a study on whole body bone mass, Martin et al found a similar dissociation between gain in height and gain in BMC, but did not report pubertal stages. ${ }^{6}$

The increase in bone mass during puberty is mainly caused by an increase in bone size, but it has also been shown in cross sectional studies that the real bone density measured by computed tomography scans ${ }^{8}$ and the size adjusted BMC measured by $\mathrm{DXA}^{9}$ increase during late puberty.

Several cross sectional studies have presented normative data for regional and whole body bone mineralisation in children and adolescents, measured by single photon absorptiometry or DXA. ${ }^{10-16}$ However, there are few longitudinal studies describing bone accretion in children and adolescents, ${ }^{5-7}$ and most studies are based on measurements of part of the skeleton only. ${ }^{5} 7$

In our study, we considered accretion in whole body BMC and bone area (BA) for both girls and boys aged 6.5-19.5 years. The aim was to analyse the relation between age, puberty, and

Table 1 Mean age over the period, annual accretion in height, and weight according to sex and pubertal stage at the first examination

\begin{tabular}{|c|c|c|c|c|c|}
\hline & \multicolumn{5}{|c|}{ Pubertal stage } \\
\hline & $\bar{I}$ & $I I$ & $I I I$ & $I V$ & $V$ \\
\hline \multicolumn{6}{|l|}{ Girls } \\
\hline Number & 38 & 26 & 20 & 30 & 56 \\
\hline \multicolumn{6}{|l|}{ Age (years) } \\
\hline 10 centile & 6.8 & 8.5 & 11.6 & 12.9 & 14.8 \\
\hline 50 centile & 8.9 & 11.2 & 13.1 & 14.9 & 16.7 \\
\hline 90 centile & 10.6 & 13.0 & 15.1 & 18.1 & 18.6 \\
\hline \multicolumn{6}{|c|}{ Height $(\mathrm{cm} /$ year $)$} \\
\hline 10 centile & 4.8 & 5.4 & 0.8 & 0.3 & -0.6 \\
\hline 50 centile & 5.8 & 7.0 & 5.1 & 1.2 & 0.4 \\
\hline 90 centile & 6.9 & 9.3 & 7.2 & 2.9 & 1.5 \\
\hline \multicolumn{6}{|c|}{ Weight (kg/year) } \\
\hline 10 centile & 1.10 & 1.27 & 1.81 & 0.00 & -2.31 \\
\hline 50 centile & 2.87 & 4.79 & 5.87 & 3.53 & 1.27 \\
\hline 90 centile & 4.78 & 8.74 & 7.93 & 6.10 & 5.95 \\
\hline \multicolumn{6}{|l|}{ Boys } \\
\hline Number & 68 & 17 & 14 & 10 & 26 \\
\hline \multicolumn{6}{|l|}{ Age (years) } \\
\hline 10 centile & 6.8 & 11.7 & 12.5 & 14.5 & 15.2 \\
\hline 50 centile & 9.1 & 12.8 & 13.2 & 15.1 & 18.1 \\
\hline 90 centile & 12.4 & 14.7 & 14.9 & 15.6 & 19.1 \\
\hline \multicolumn{6}{|c|}{ Height $(\mathrm{cm} /$ year $)$} \\
\hline 10 centile & 4.3 & 4.9 & 8.4 & 2.7 & 0.0 \\
\hline 50 centile & 5.4 & 7.5 & 9.8 & 5.6 & 1.0 \\
\hline 90 centile & 7.1 & 12.1 & 11.1 & 7.4 & 2.8 \\
\hline \multicolumn{6}{|c|}{ Weight (kg/year) } \\
\hline 10 centile & 1.51 & 3.14 & 4.89 & 0.55 & -0.79 \\
\hline 50 centile & 3.10 & 6.10 & 7.80 & 6.61 & 1.48 \\
\hline 90 centile & 5.21 & 9.28 & 10.02 & 8.42 & 8.14 \\
\hline
\end{tabular}


Table 2 Annual accretion in bone mineral content $(B M C)$, bone area, and bone calcium according to sex and pubertal stage at the first examination

\begin{tabular}{|c|c|c|c|c|c|}
\hline & \multicolumn{5}{|c|}{ Pubertal stage } \\
\hline & $I$ & $I I$ & $I I I$ & $I V$ & $V$ \\
\hline \multicolumn{6}{|l|}{ Girls } \\
\hline Number & 38 & 26 & 20 & 30 & 56 \\
\hline \multicolumn{6}{|l|}{ BMC (g/year) } \\
\hline 10 centile & 67 & 80 & 81 & 7 & -46 \\
\hline 50 centile & 112 & 218 & 249 & 132 & 69 \\
\hline 90 centile & 188 & 303 & 343 & 310 & 199 \\
\hline \multicolumn{6}{|c|}{ Bone area $\left(\mathrm{cm}^{2} /\right.$ year $)$} \\
\hline 10 centile & 74 & 76 & 27 & -6 & -61 \\
\hline 50 centile & 112 & 180 & 197 & 78 & 33 \\
\hline 90 centile & 164 & 261 & 264 & 178 & 101 \\
\hline \multicolumn{6}{|c|}{ Calcium (mg/day) } \\
\hline 10 centile & 58.9 & 70.2 & 71.8 & 6.2 & -40.5 \\
\hline 50 centile & 98.9 & 192.6 & 220.1 & 116.4 & 60.8 \\
\hline 90 centile & 165.8 & 267.0 & 302.2 & 273.6 & 175.1 \\
\hline \multicolumn{6}{|c|}{ Boys } \\
\hline Number & 68 & 17 & 14 & 10 & 26 \\
\hline \multicolumn{6}{|l|}{ BMC (g/year) } \\
\hline 10 centile & 76 & 143 & 215 & 108 & 12 \\
\hline 50 centile & 122 & 212 & 359 & 284 & 110 \\
\hline 90 centile & 179 & 398 & 438 & 377 & 201 \\
\hline \multicolumn{6}{|c|}{ Bone area $\left(\mathrm{cm}^{2} /\right.$ year $)$} \\
\hline 10 centile & 77 & 131 & 151 & 30 & 1 \\
\hline 50 centile & 115 & 190 & 252 & 174 & 36 \\
\hline 90 centile & 158 & 297 & 300 & 256 & 95 \\
\hline \multicolumn{6}{|c|}{ Calcium (mg/day) } \\
\hline 10 centile & 67.0 & 125.9 & 189.9 & 95.1 & 10.8 \\
\hline 50 centile & 107.6 & 187.1 & 316.7 & 250.8 & 96.8 \\
\hline 90 centile & 157.8 & 350.9 & 386.1 & 332.7 & 177.6 \\
\hline
\end{tabular}

growth in bone size and BMC to help in the understanding of the biology of bone mineralisation during puberty. Furthermore, we hoped to provide data for age dependent growth in bone size and BMC in healthy children and adolescents, for use in research and clinical practice.

\section{Subjects and methods}

SUBJECTS

Our study is based on a one year follow up of a previously published cross sectional study with school children from five schools in Copenhagen. ${ }^{10}$ Of the 343 (201 girls, 142 boys) healthy individuals participating in the cross sectional study, 97\% (192 girls, 140 boys) were re-examined one year later (mean (SD), 1.02 years (0.07)). Table 1 gives basic information on the study population, but more detailed information has been published previously. ${ }^{10}$

PUBERTY AND ANTHROPOMETRY

One hundred and seventy six girls and 137 boys participating in the follow up study had their pubertal stages assessed according to Tanner ${ }^{17}{ }^{18}$ at the first examination. Breast development in girls and pubic hair development in boys were used to assess pubertal stage. Height and weight were measured before DXA scanning. Height was determined to the nearest $1 \mathrm{~mm}$ using a stadiometer. Weight was measured to the nearest $0.1 \mathrm{~kg}$ using a digital electronic instrument. Subjects wore only pants and a cotton T-shirt when weighed.

BONE MINERAL ASSESSMENT

Whole body BMC (measured in grams of hydroxyapatite) and bone size expressed as anterior-posterior projected BA (measured in $\mathrm{cm}^{2}$ ) were determined by DXA scanning using a Hologic 1000/W (Hologic Inc, Waltham, Mas- sachusetts, USA). For analysis, software version 5.61 was used. Subjects wore only pants and a cotton T-shirt during the scan. For quality control, spine phantoms were scanned daily. The coefficients of variation for these BMC and BA measurements on a spine phantom over a period of two years $(n=358)$ were $0.37 \%$ and $0.28 \%$, respectively. For each scanning the entrance radiation dose level was $15 \mu \mathrm{Sv}$, with an effective dose not more than $10 \mu \mathrm{Sv}$, equal to about one day's background radiation in Denmark.

STATISTICAL METHODS

The weight for height and the height for age distributions of the individuals were compared with a Danish sex specific reference. ${ }^{19}$ The result of this analysis has been reported earlier ${ }^{10}$; it showed that the children were taller for age and heavier for height compared with the 20 year old Danish reference data. ${ }^{19}$ This is in accordance with the general pattern that both the height of the children and the prevalence of overweight children has increased in Scandinavia. ${ }^{20-22}$

Annual gain in height $(\Delta \mathrm{H}(\mathrm{cm} /$ year $))$, weight $(\Delta \mathrm{W}$ (kg/year)), BMC ( $\triangle \mathrm{BMC}(\mathrm{g} /$ year)), and BA $\left(\triangle \mathrm{BA}\left(\mathrm{cm}^{2} /\right.\right.$ year$\left.)\right)$ were calculated from the two measurements corrected to exactly one year by dividing the difference in measurement by the difference in age (years). Annual bone calcium accretion rates expressed as mg calcium/day $(\Delta \mathrm{Ca})$ according to pubertal stages were calculated assuming that $32.2 \%$
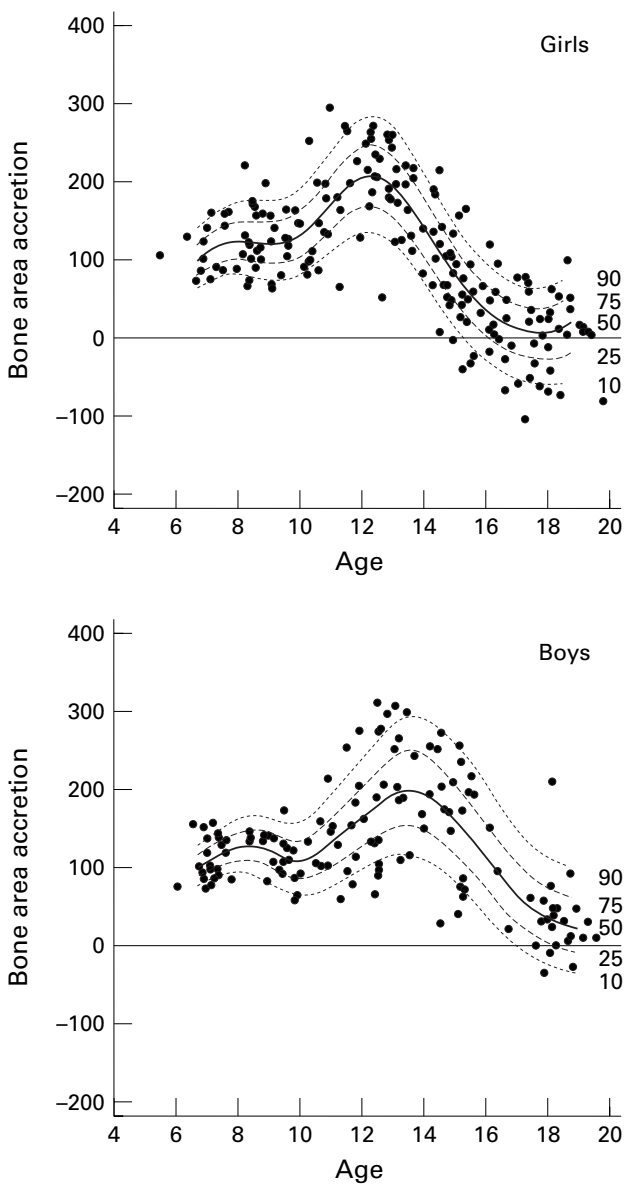

Figure 1 Centile curves for annual whole body bone area accretion ( $\mathrm{cm}^{2} /$ year) according to sex and age (years). 
of the BMC measured by Hologic instruments is calcium $^{23}(\Delta \mathrm{Ca}(\mathrm{mg} /$ day $)=(\Delta \mathrm{BMC}(\mathrm{g} /$ year) $\left.\left.{ }^{\star} 1000 \star 0.322\right) / 365\right)$.

We derived smooth centile curves for $\triangle \mathrm{BA}$ and $\triangle B M C$ versus mean age over the period using the LMS method. ${ }^{24}$ This summarises the distribution of the dependent variable (for example, $\triangle \mathrm{BMC}$ ) given the covariate by a BoxCox power (L), depending on the skewness of the distribution, the median (M), and the coefficient of variation (S), giving smooth curves for the dependence of L, M, and S on the covariate. In our study a modified version adding 300 to the BA and BMC accretion was used, because negative accretion occurred; thus, the centiles are based on the assumption that the variable $Z$, defined as:

$$
\begin{gathered}
Z=\frac{\left(\frac{\Delta B M C+300}{M+300}\right)^{L}-1}{L S} \text { for } L \neq 0 \\
Z=\frac{1}{S} \cdot \log _{e}\left(\frac{\Delta B M C+300}{M+300}\right) \text { for } L=0
\end{gathered}
$$

is standard normally distributed. Therefore, these formulae may be used to calculate the $\mathrm{Z}$ score of an observed value of $\triangle \mathrm{BMC}$ or $\triangle \mathrm{BA}$ given the value of the covariate. The range of the
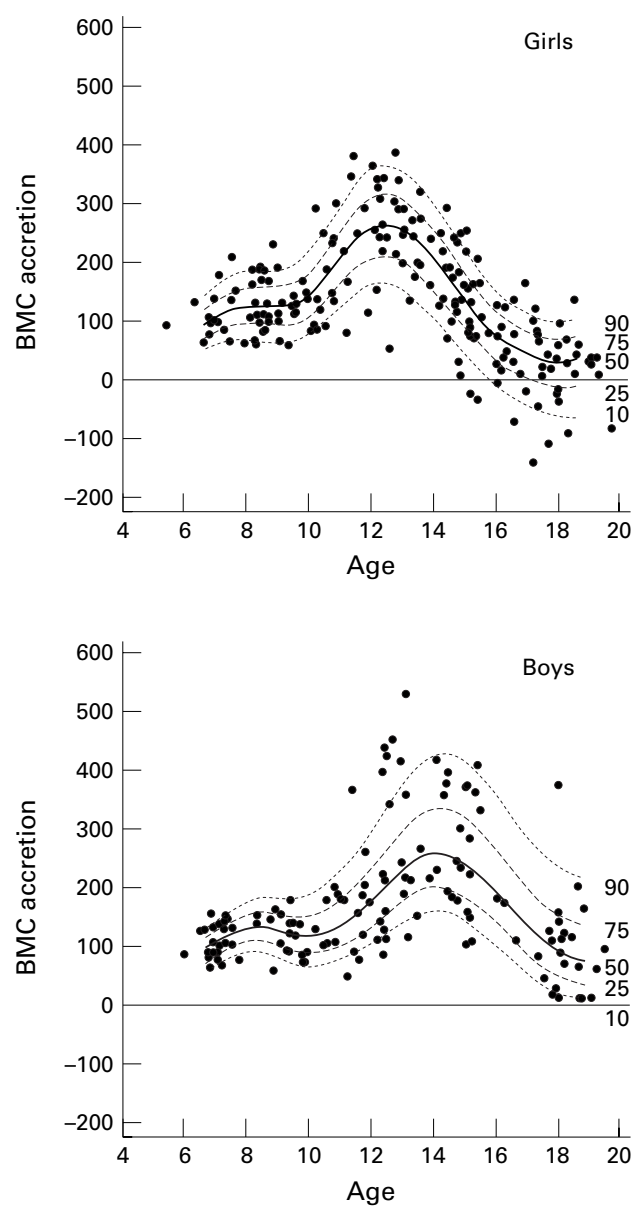

Figure 2 Centile curves for annual whole body bone mineral content (BMC) accretion (g/year) according to sex and age (years). covariate age was reduced to eliminate edge effects caused by single extreme values. Thus, we considered the age interval 6.5-19.5 years (both sexes).

The influence of pubertal stage on $\triangle \mathrm{BA}$ and $\triangle B M C$ was estimated by maximum likelihood in a linear mixed model allowing the variance to depend on pubertal stage. The pubertal stages were entered as four binary covariates, each measuring the change from one pubertal stage to the next. All tests were based on the likelihood ratio test statistic.

\section{Results}

Table 2 shows annual accretion rates in BMC (g/year), BA ( $\mathrm{cm}^{2} /$ year), and calcium (mg/day) according to sex and pubertal stage at first examination.

GAIN IN BMC AND GAIN IN BA RELATED TO AGE AND PUBERTAL STAGES

The sex specific, age dependent centile curves for $\triangle \mathrm{BA}$ (fig 1) and $\triangle \mathrm{BMC}$ (fig 2) showed a large variation around the median, especially for the boys between 11 and 16 years. The Box-Cox power (L), the median (M), and the coefficient of variation (S) for $\Delta \mathrm{BA}\left(\mathrm{cm}^{2} /\right.$ year) and $\triangle B M C$ (g/year) by sex and age are shown in tables 3 and 4 , respectively. Using these values, it is possible to calculate $Z$ scores for individual children. The girls' curves peaked earlier than those of the boys' for both $\triangle \mathrm{BA}$ (fig 1) and $\triangle B M C$ (fig 2). The peak ages for $\triangle B A$ were 12.3 and 13.4 years for girls and boys, respectively, whereas the peak ages for $\triangle \mathrm{BMC}$ were 12.5 and 14.2 years, respectively. The $\triangle \mathrm{BA}$ and $\triangle \mathrm{BMC}$ curves were of similar shape except that $\triangle \mathrm{BA}$ peaked earlier than $\triangle \mathrm{BMC}$ for both girls and boys, most distinctly in boys (figs 1 and 2). Eight boys between the ages of 11 and 13.5 years had a $\triangle B M C$ above the 90 th centile. Six of these boys $(75 \%)$ were in pubertal stage III, while only $8 \%$ of the boys below the 90 th

Table 3 Annual bone area (BA) accretion for age. The parameters $M$ (median), $L$, and $S$ used in the modified formula for $B A$ accretion ( $\mathrm{cm}^{2} /$ year) by sex and age (see

\begin{tabular}{|c|c|c|c|c|c|c|}
\hline \multirow{2}{*}{$\begin{array}{l}\text { Age } \\
\text { (years) }\end{array}$} & \multicolumn{2}{|l|}{$M$} & \multicolumn{2}{|l|}{$L$} & \multicolumn{2}{|l|}{$S$} \\
\hline & Boys & Girls & Boys & Girls & Boys & Girls \\
\hline 7.0 & 109 & 109 & 0.488 & -0.821 & 0.053 & 0.076 \\
\hline 7.5 & 119 & 119 & 0.458 & -0.696 & 0.059 & 0.080 \\
\hline 8.0 & 125 & 123 & 0.429 & -0.571 & 0.064 & 0.084 \\
\hline 8.5 & 127 & 123 & 0.399 & -0.446 & 0.070 & 0.088 \\
\hline 9.0 & 121 & 122 & 0.370 & -0.321 & 0.076 & 0.092 \\
\hline 9.5 & 112 & 124 & 0.340 & -0.196 & 0.083 & 0.096 \\
\hline 10.0 & 109 & 133 & 0.310 & -0.071 & 0.091 & 0.100 \\
\hline 10.5 & 118 & 150 & 0.280 & 0.054 & 0.098 & 0.103 \\
\hline 11.0 & 133 & 172 & 0.250 & 0.178 & 0.106 & 0.107 \\
\hline 11.5 & 148 & 193 & 0.220 & 0.302 & 0.113 & 0.110 \\
\hline 12.0 & 164 & 205 & 0.190 & 0.426 & 0.120 & 0.113 \\
\hline 12.5 & 180 & 206 & 0.159 & 0.550 & 0.127 & 0.116 \\
\hline 13.0 & 195 & 193 & 0.128 & 0.673 & 0.132 & 0.119 \\
\hline 13.5 & 199 & 170 & 0.096 & 0.796 & 0.137 & 0.123 \\
\hline 14.0 & 193 & 141 & 0.065 & 0.920 & 0.141 & 0.126 \\
\hline 14.5 & 180 & 111 & 0.032 & 1.042 & 0.145 & 0.130 \\
\hline 15.0 & 160 & 81 & -0.001 & 1.164 & 0.147 & 0.134 \\
\hline 15.5 & 139 & 55 & -0.034 & 1.287 & 0.150 & 0.138 \\
\hline 16.0 & 114 & 37 & -0.068 & 1.409 & 0.151 & 0.141 \\
\hline 16.5 & 89 & 23 & -0.102 & 1.531 & 0.153 & 0.145 \\
\hline 17.0 & 68 & 14 & -0.137 & 1.654 & 0.154 & 0.149 \\
\hline 17.5 & 50 & 9 & -0.172 & 1.776 & 0.154 & 0.152 \\
\hline 18.0 & 39 & 9 & -0.207 & 1.899 & 0.155 & 0.156 \\
\hline 18.5 & 32 & 17 & -0.241 & 2.021 & 0.156 & 0.159 \\
\hline
\end{tabular}
Statistical Methods section) 
Table 4 Annual bone mineral content (BMC) accretion for age. The parameters $M$ (median), $L$, and $S$ used in the modified formula for BMC accretion (g/year) by sex and age (see Statistical Methods section)

\begin{tabular}{|c|c|c|c|c|c|c|}
\hline \multirow{2}{*}{$\begin{array}{l}\text { Age } \\
\text { (years) }\end{array}$} & \multicolumn{2}{|l|}{$M$} & \multicolumn{2}{|l|}{$L$} & \multicolumn{2}{|l|}{$S$} \\
\hline & Boys & Girls & Boys & Girls & Boys & Girls \\
\hline 7.0 & 104 & 107 & -0.895 & -0.605 & 0.064 & 0.092 \\
\hline 7.5 & 118 & 119 & -0.921 & -0.469 & 0.071 & 0.097 \\
\hline 8.0 & 127 & 124 & -0.948 & -0.334 & 0.078 & 0.102 \\
\hline 8.5 & 131 & 126 & -0.974 & -0.199 & 0.086 & 0.107 \\
\hline 9.0 & 126 & 126 & -1.000 & -0.064 & 0.094 & 0.112 \\
\hline 9.5 & 118 & 128 & -1.027 & 0.071 & 0.103 & 0.117 \\
\hline 10.0 & 116 & 143 & -1.053 & 0.206 & 0.112 & 0.121 \\
\hline 10.5 & 125 & 170 & -1.080 & 0.342 & 0.122 & 0.126 \\
\hline 11.0 & 137 & 203 & -1.106 & 0.476 & 0.132 & 0.130 \\
\hline 11.5 & 151 & 235 & -1.132 & 0.611 & 0.141 & 0.134 \\
\hline 12.0 & 171 & 255 & -1.158 & 0.745 & 0.149 & 0.137 \\
\hline 12.5 & 198 & 263 & -1.184 & 0.879 & 0.157 & 0.140 \\
\hline 13.0 & 226 & 255 & -1.209 & 1.013 & 0.163 & 0.144 \\
\hline 13.5 & 247 & 236 & -1.235 & 1.146 & 0.169 & 0.147 \\
\hline 14.0 & 258 & 208 & -1.260 & 1.281 & 0.174 & 0.150 \\
\hline 14.5 & 256 & 177 & -1.285 & 1.412 & 0.177 & 0.153 \\
\hline 15.0 & 243 & 141 & -1.310 & 1.546 & 0.181 & 0.157 \\
\hline 15.5 & 223 & 107 & -1.335 & 1.679 & 0.183 & 0.160 \\
\hline 16.0 & 197 & 79 & -1.360 & 1.811 & 0.186 & 0.164 \\
\hline 16.5 & 167 & 60 & -1.385 & 1.944 & 0.188 & 0.168 \\
\hline 17.0 & 138 & 49 & -1.410 & 2.077 & 0.189 & 0.171 \\
\hline 17.5 & 112 & 37 & -1.435 & 2.209 & 0.191 & 0.175 \\
\hline 18.0 & 95 & 30 & -1.460 & 2.342 & 0.192 & 0.178 \\
\hline 18.5 & 84 & 33 & -1.485 & 2.474 & 0.194 & 0.182 \\
\hline
\end{tabular}

centile were in pubertal stage III. The youngest boys in pubertal stage III $(<13.5$ years; $n=8)$ had a particularly high $\triangle \mathrm{BMC}$, with a median $\mathrm{Z}$ score of 1.72 (range, -0.54 to 2.29 ).

$\triangle \mathrm{BA}$ and $\triangle \mathrm{BMC}$ were significantly associated with pubertal stage for girls $\left(\chi^{2}(4)=88.54\right.$ and $\quad \chi^{2}(4)=64.20, \quad$ respectively; both $\mathrm{p}<0.0001)$ and boys $\left(\chi^{2}(4)=67.12\right.$ and $\chi^{2}(4)=55.29$, respectively; both $\left.\mathrm{p}<0.0001\right)$. $\triangle \mathrm{BA}$ was highest in pubertal stage III for both girls and boys, but not significantly different from pubertal stage II in girls and boys (girls: $\chi^{2}(1)=0.187, \mathrm{p}=0.67$; boys: $\chi^{2}(1)=2.07$, $\mathrm{p}=0.15)$, and borderline significantly different from pubertal stage IV in boys $\left(\chi^{2}(1)=3.52\right.$, $\mathrm{p}=0.06) . \triangle \mathrm{BMC}$ was highest in pubertal stage III for both girls and boys, but only borderline significantly different from pubertal stage II in girls $\left(\chi^{2}(1)=2.83, \mathrm{p}=0.09\right)$, and pubertal stage IV in boys $\left(\chi^{2}(1)=2.975, p=0.08\right)$.

\section{Discussion}

Our longitudinal study on whole body bone mineralisation confirmed the close relation between pubertal stages and gain in BMC and bone size described previously for regional bone mineralisation. Our study showed a dissociation in time between peak growth in bone size and the peak growth in BMC. To our knowledge, this is the first study reporting longitudinal data on whole body $\mathrm{BA}$ in a wide age range for both girls and boys.

We have only presented centile curves for whole body BA accretion and for whole body $\mathrm{BMC}$ accretion. We chose not to use bone mineral density (BMD) calculated as $\mathrm{BMC} / \mathrm{BA}$ because BMD measured with anteriorposterior osteodensitometry represents a mixture of true density and skeletal size, as described previously. ${ }^{10}{ }^{25-27}$

We suggest that our data may be used for assessing growth of whole body BMC and BA of children for clinical or research purposes.
However, for young boys in pubertal stage III, extremely high $\mathrm{Z}$ scores for BMC accretion may be anticipated. Attained BA and BMC can be evaluated using the data based on the first examination of these children. ${ }^{10}$ However, there are some limitations to the use of our dataset as a reference because of the limited number of children in each age and sex group, and because only $25 \%$ of the children approached agreed to participate, as described in more detail previously. ${ }^{10}$ Nevertheless, it is one of the most comprehensive sets of data on whole body measurements available at present. For daily clinical use, an individual may be plotted on centile charts like those shown in figs 1 and 2. (Single copies of large centile charts can be obtained from the authors.) If a more accurate centile or $\mathrm{Z}$ score is required, the $\mathrm{Z}$ score can be calculated using the equations presented above by inserting the measured $\triangle \mathrm{BA}$ or $\triangle \mathrm{BMC}$ and $\mathrm{L}, \mathrm{M}$, and $\mathrm{S}$ values corresponding to the mean age over the period presented in tables 3 and 4 . When using these data for calculation of $\mathrm{Z}$ scores for $\triangle \mathrm{BA}$ and $\triangle \mathrm{BMC}$, the calculation of $\triangle \mathrm{BA}$ and $\triangle \mathrm{BMC}$ should be based on measurements determined with an approximate one year interval corrected exactly to one year, as described above.

Our data indicate that the median accretion rates for both $\triangle \mathrm{BA}$ and $\triangle \mathrm{BMC}$ are similar for the two sexes before puberty (tables 3 and 4). This is in agreement with Theintz et al, ${ }^{5}$ who found no sex differences between the ages of 9 and 11 years for bone mass accretion in lumbar spine, femoral neck, and femoral shaft. Recently, Martin et al have published data on whole body BMC accretion also showing that the accretion rates were similar for girls and boys aged $9-10$ years (130 g/year). ${ }^{6}$

We observed an earlier age for peak accretion in both $\triangle \mathrm{BA}$ and $\triangle \mathrm{BMC}$ for girls (12.3 and 12.5 years, respectively) compared with boys (13.4 and 14.2 years, respectively), which is in agreement with the earlier age of puberty in girls. An earlier age for the regional bone mass accretion peak for girls compared with boys was also found by Theintz et al. ${ }^{5}$ The age at peak accretion in both $\triangle \mathrm{BA}$ and $\triangle \mathrm{BMC}$ in our study was similar to that seen by Martin and colleagues $^{6}$ in Canadian children, where the difference in age between peak in $\triangle \mathrm{BA}$ and $\triangle \mathrm{BMC}$ was also most pronounced in boys. The earlier peak in BA accretion rate in relation to the peak in BMC accretion rate in both girls and boys indicated a dissociation between growth in bone size and growth in BMC during puberty. The dissociation between accretion rate in BA and BMC is also supported by a study showing that the fracture rate in children is highest around peak height velocity, and this could not be explained by increase in physical activity. ${ }^{28}$ Blimkie et al found that a lag in cortical bone thickness and mineralisation relative to linear skeletal growth appeared to be the predominant factors associated with the increased fracture incidence in Belgian boys during the growth spurt. ${ }^{29}$ This dissociation between growth in bone size and growth in $\mathrm{BMC}$ is in agreement with our longitudinal data. In summary, studies of both regional and 
whole body mineralisation corroborate the dissociation in time between growth in bone size and growth in BMC during puberty that was pointed out many years ago by Krabbe et al. ${ }^{30}$

Few longitudinal whole body DXA datasets have been published. Lloyd and colleagues ${ }^{31}$ published data from an intervention study of 12 year old girls in mid-puberty using a QDR Hologic $1000 / W$, as used in our study, although the software version was not mentioned. From their data, a BMC accretion rate of $257 \mathrm{~g} /$ year can be calculated, which is similar to the median $\triangle \mathrm{BMC}$ for 12 year old girls in our study (255 g/year). In the study of Martin et al, ${ }^{6}$ in which bone measurements were obtained by a QDR Hologic 2000 (software version $5.56 \mathrm{~A}$ ), the peak accretion for $\triangle \mathrm{BA}$ in boys and girls was 212 and $174 \mathrm{~cm}^{2} /$ year, respectively, which is below our values for girls and a little above our values for boys. In the same study, the peak accretion for $\triangle \mathrm{BMC}$ in boys and girls was 320 and $240 \mathrm{~g} /$ year, respectively, which is similar to our values for girls but above our values for boys. When our data were expressed according to pubertal stage, the values in pubertal stage III were similar to the peak values in the study by Martin et al, ${ }^{6}$ so the difference in accretion values according to age might be caused by differences in the timing of puberty between the two studies.

Our data on bone calcium accretion (table 2) showed that in normal children in midpuberty, a relatively high calcium retention is needed. The bone calcium accretion values calculated from our DXA measurements are similar to the values obtained by others using balance studies. Jackman et al examined the relation between calcium retention and calcium intake in girls aged $12-14$ years (mean, 12.7) and found an increase in retention with increase in calcium intake. ${ }^{4}$ The retention was measured by balance studies over two weeks. For a calcium intake of $\sim 1100 \mathrm{mg} /$ day in that study, the calcium retention was $\sim 300 \mathrm{mg}$ /day for girls at menarche. In our study, girls in Tanner stage III had a median calcium intake of $1146 \mathrm{mg} / \mathrm{day}^{32}$ and a median calcium retention of $220 \mathrm{mg} /$ day over the following year, which means that the retention in shorter periods was probably considerably higher. Thus, in both balance and DXA studies, it has been shown that calcium retention is high in mid-puberty. Therefore, during puberty, children with a low calcium intake need a high calcium absorption rate to obtain an average bone mineralisation. Most children in Western countries who do not drink milk will have a very low calcium intake, typically $300-400 \mathrm{mg} /$ day. $^{33}$ If their calcium intake is below $500 \mathrm{mg} /$ day, more than $50 \%$ of the ingested calcium should then be retained in the bones to obtain an average mineral accretion. It is not known to what extent children can adapt to a low calcium intake by increasing the absorption capacity, but the high calcium retention in normal puberty indicates that a low calcium intake during puberty may limit bone mineralisation. Whether a negative influence on bone mineralisation during puberty will also affect peak bone mass negatively is unknown because it has not been shown to what extent children can catch up later in adolescence. To examine this further, longitudinal studies are needed that follow children who have a varying calcium intake from before puberty to adulthood.

In conclusion, we have presented centile curves for annual bone area and bone mineral content accretion according to sex and age in school age children and adolescents. We found a very strong relation between pubertal stages and both bone size and bone mineral accretion. In puberty we observed a dissociation in time between the peak in bone size accretion and the peak in bone mineral accretion.

This study was financed by FØTEK (The Danish Research and Development Programme for Food Technology) and the Danish Dairy Research Foundation. We are grateful to B Hermansen for valuable assistance with the DXA scanning.

1 Anonymous. Consensus development conference: diagnois, prophylaxis, and treatment of osteoporosis. Am $\mathcal{F}$ Med 1993;94:646-50.

2 Hansen MA, Overgaard K, Riis BJ, Christiansen C. Role of peak bone mass and bone loss in postmenopausal osteoporosis: 12 year study. BMF 1991;303:961-4.

3 Matkovic V, Heaney RP. Calcium balance during human growth: evidence for threshold behavior. Am $\mathcal{f}$ Clin Nutr 1992;55:992-6.

4 Jackman LA, Millane SS, Martin BR, et al. Calcium retention in relation to calcium intake and postmenarcheal
age in adolescent females. Am F Clin Nutr 1997;66:327-33.

5 Theintz G, Buchs B, Rizzoli R, et al. Longitudinal monitoring of bone mass accumulation in healthy adolescents: evidence for a marked reduction after 16 years of age at the dence for a marked reduction after 16 years of age at the levels of lumbar spine and femoral neck in

6 Martin AD, Bailey DA, McKay HA, Whitting S. Bone mineral and calcium accretion during puberty. Am f Clin Nutr 1997;66:611-15.

7 Fournier P-E, Rizzoli R, Slosman D-O, Theintz G, Bonjour $\mathrm{J}-\mathrm{P}$. Asynchrony between the rates of standing height gain and bone mass accumulation during puberty. Osteoporos Int 1997;7:525-32.

8 Gilsanz V, Gibbens DT, Roe TF, et al. Vertebral bone density in children: effect of puberty. Radiology 1988;166:847-50.

9 Mølgaard C, Thomsen BL, Michaelsen KF. Influence of weight, age and puberty on bone size and bone mineral content in healthy children and adolescents. Acta Paediatr 1998;87:494-9.

10 Mølgaard C, Thomsen BL, Prentice A, Cole TJ, Michaelsen KF. Whole body bone mineral content in healthy children KF. Whole body bone mineral content in healthy

11 Glastre C, Braillon P, David L, Cochat P, Meunier PJ, Delmas PD. Measurement of bone mineral content of the lumbar spine by dual energy $x$-ray absorptiometry in normal children: correlations with growth parameters. $\mathcal{F}$ Clin Endocrinol Metab 1990;70:1330-3.

12 Bishop NJ, dePriester JA, Cole TJ, Lucas A. Reference values for radial bone width and mineral content using single photon absorptiometry in healthy children aged 4 to 10 years. Acta Paediatr 1992;81:463-8.

13 Katzman DK, Bachrach LK, Carter DR, Marcus R. Clinical and anthropometric correlates of bone mineral acquisition in healthy adolescent girls. I Clin Endocrinol Metab 1991;73:1332-9.

14 Lu PW, Briody JN, Ogle GD, et al. Bone mineral density of total body, spine, and femoral neck in children and young adults: a cross-sectional and longitudinal study. f Bone Miner Res 1994;9:1451-8.

15 Faulkner RA, Bailey DA, Drinkwater DT, Wilkinson AA, Houston CS, McKay HA. Regional and total body bone mineral content, bone mineral density, and total body tissue composition in children 8-16 years of age. Calcif Tissue Int 1993;53:7-12.

16 Hannan WJ, Cowen SJ, Wrate RM, Barton J. Improved prediction of bone mineral content and density. Arch Dis Child 1995;72:147-9.

17 Marshall WA, Tanner JM. Variations in the pattern of pubertal changes in boys. Arch Dis Child 1970;45:13-23.

18 Marshall WA, Tanner JM. Variations in pattern of pubertal changes in girls. Arch Dis Child 1969;44:291-303.

19 Andersen E, Hutchings B, Jansen J, Nyholm M. Heights and weights of Danish children. [Danish]. Ugeskr Laeger 1982;144:1760-5.

20 Thomsen BL, Ekstrøm C, Sørensen TIA. Changes in the distribution of weight, height and body mass index $(\mathrm{BMI}=\mathrm{W} / \mathrm{H} 2)$ at ages 7 to 14 years in a population of danish boys born 1930 through 1966. Int $\mathcal{f}$ Obes 19anish 19:52. 
21 Cernerud L. Height and body mass index of seven-year-old Stockholm schoolchildren from 1940 to 1990 . Acta PaediStockholm schoolch
atr 1993;82:304-5.

22 Lindgren G, Strandell A, Cole T, Healy M, Tanner J. Swedish population reference standards for height, weight and body mass index attained at 6 to 16 years (girls) or 19 years (boys). Acta Paediatr 1995;84:1019-28

23 Ellis KJ, Shypailo RJ, Hergenroeder A, Perez M, Abrams S. Total body calcium and bone mineral content: comparison of dual-energy x-ray absorptiometry with neutron activation analysis. $\mathcal{F}$ Bone Miner Res 1996;11:843-8. 24 Cole TJ, Green PJ. Smoothing reference centile curves: the
LMS method and penalized likelihood. Stat Med 1992;11: 1305-19.

25 Carter DR, Bouxsein ML, Marcus R. New approaches for interpreting projected bone densitometry data. I Bone Miner Res 1992;7:137-45.

26 Prentice A, Parsons TJ, Cole TJ. Uncritical use of bone mineral density in absorptiometry may lead to size-related artifacts in the identification of bone mineral determinants. Am f Clin Nutr 1994;60:837-42.

27 Nielsen SP, Hermansen F, Barenholdt O. Interpretation of lumbar spine densitometry in women with fractures. Osteoporos Int 1993;3:276-82.
28 Bailey DA, Wedge JH, McCulloch RG, Martin AD, Bernhardson SC. Epidemiology of fractures of the distal end of the radius in children as associated with growth. $\mathcal{F}$ Bone foint Surg [Am] 1989;71A:1225-31.

29 Blimkie CJ, Lefevre J, Beunen GP, Renson R, Dequeker J, Van Damme P. Fractures, physical activity, and growth velocity in adolescent Belgian boys. Med Sci Sports Exerc 1993;25:801-8.

30 Krabbe S, Christiansen C, Rodbro P, Transbol I. Effect of puberty on rates of bone growth and mineralisation: with observations in male delayed puberty. Arch Dis Child 1979; observations

31 Lloyd T, Andon MB, Rollings N, et al. Calcium supplementation and bone mineral density in adolescent girls. $\mathcal{F A M A}$ 1993;270:841-4.

32 Mølgaard C, Sandström B, Michaelsen KF. Whole body bone mineral content $(\mathrm{BMC})$ and calcium intake in healthy children. F Pediatr Gastroenterol Nutr 1996;22:436.

33 Mølgaard C. Bone mineralisation during growth. The influence of growth, puberty and calcium intake [in Danish].
PhD Thesis. Research Department of Human Nutrition, The Royal Veterinary and Agricultural University, Fredenksberg, Denmark, 1996. 